\title{
The Molecular Epidemiology and Clinical Phylogenetics of Rhinoviruses among Paediatric Cases in Sydney, Australia.
}

\author{
Dillon Adam ${ }^{1}$, Xin Chen ${ }^{1}$, Matthew Scotch $^{2}$, C. Raina MacIntyre ${ }^{3}$, Dominic Dwyer ${ }^{4}$, and \\ Jen $\mathrm{Kok}^{4}$ \\ ${ }^{1} \mathrm{UNSW}$ \\ ${ }^{2}$ Arizona State University \\ ${ }^{3}$ University of New South Wales \\ ${ }^{4}$ Westmead Hospital
}

November 23, 2020

\begin{abstract}
Background Rhinoviruses (RV) represent the most common aetiological agent of all acute respiratory tract infections across all age groups and a significant burden of disease among children. Recent studies have shown that RV-A and RV-C species are associated with varying degrees of disease severity and clinical symptoms. Methods In this study, we uncovered potential associations between RV species and subtypes, and clinical disease severity using a matched dataset of 52 RV isolates sampled from children (<18 years) in Sydney, Australia between 2006 and 2009 using epidemiological and phylogenetic methods. Results We found that RV-C was significantly more likely to be isolated from paediatric cases under two years of age compared to RVA, although no significant differences in recorded symptoms were observed. Significant phylogenetic-trait associations between age and the VP4/VP2 capsid protein phylogeny suggests age-specific variations in infectivity among subtypes might also be possible. Conclusions This study adds to the growing body of epidemiological evidence concerning RV. Improving surveillance and testing for RV, including routine whole genome sequencing may improve our understanding of the varied diseashe outcomes of RV species and subtypes. Future studies could aim to identify specific genetic markers associated with age-specific infectivity of RV which could inform treatment practices and public health surveillance of RV.
\end{abstract}

Title: The Molecular Epidemiology and Clinical Phylogenetics of Rhinoviruses among Paediatric Cases in Sydney, Australia.

Running title : Molecular Epidemiology of Rhinoviruses in Sydney

Authors : Dillon Charles Adam ${ }^{1}$, Xin $\mathrm{Chen}^{{ }^{*}}$, Matthew $\operatorname{Scotch}^{1,2,3}$, Chandini Raina MacIntyre ${ }^{1,4}$, Dominic Dwyer $^{5}$, Jen $\mathrm{Kok}^{5}$

\section{Affiliations}

1. Biosecurity Program, The Kirby Institute, Faculty of Medicine, University of New South Wales, Sydney, NSW 2052, Australia.

2. Biodesign Center for Environmental Health Engineering, Biodesign Institute, Arizona State University, Tempe, AZ 85281, USA.

3. College of Health Solutions, Arizona State University, Phoenix, AZ 85004, USA.

4. College of Public Service \& Community Solutions, Arizona State University, Tempe, AZ 85004, USA.

5. Institute for Clinical Pathology and Medical Research, NSW Health Pathology, Westmead Hospital and University of Sydney, Sydney, NSW 2145, Australia 


\section{* Corresponding Author}

Xin Chen Address: Biosecurity Program, The Kirby Institute, Faculty of Medicine, University of New South Wales, Sydney, NSW 2052, Australia. Email: xinjessiechen@protonmail.com

\section{Word count}

Abstract: 168 words. Main text: 2421 words.

\section{Declarations}

Ethics approval and consent to participate

The human sequence data used in this study were publicly available from GenBank. This study was approved by the UNSW Human Research Ethics Committee (HC17284).

\section{Funding}

This work was supported by a grant from the NHRMC Centre for Research Excellence in Integrated Systems for Epidemic Response (ISER) [grant number 1107393] to DCA, XC and CRM. DCA and CRM are also supported by an NHMRC Postgraduate Scholarship [grant number 1169037] and NHMRC Principal Research Fellowship [grant number 1137582] respectively. MS is also supported by the National Library of Medicine of the National Institutes of Health under [grant number R01LM012080]. The content is solely the responsibility of the authors and does not necessarily represent the official views of the National Institutes of Health. The funders had no role in the study's conception, design, data collection and interpretation, or the decision to submit the work for publication.

\section{Acknowledgments}

We would like to acknowledge the support for DCA through an Australian Government Research Training Program Scholarship. This work was also like to acknowledge from the tri-university (Arizona State University, King's College London, and University of New South Wales) PLuS Alliance.

\section{Conflicts of interest}

CRM has received funding for investigator-driven research from Merck, GSK and Seqirus, and support for laboratory testing unrelated to this study from Pfizer. CRM has also been on advisory boards for the same companies. DCA, XC, MS, DD and JK have no competing interests to declare.

Availability of data and materials

All data generated or analysed during this study are included in this published article and its supplementary information.

\section{Authors' contributions}

DCA was a major contributor in data collection, analysis and writing the manuscript. MS, CRM, DD and JK have made substantial contributions to the conception and design of the study. MS and CRM revised the manuscript. XC contributed to data validation and manuscript submission. All authors read and approved the final manuscript.

\section{Patient consent statement}

Not applicable.

Permission to reproduce material from other sources

Not applicable.

\section{Hosted file}


rhinovirus-manuscript (22-Nov-2020).pdf available at https://authorea.com/users/378105/ articles/494672-the-molecular-epidemiology-and-clinical-phylogenetics-of-rhinovirusesamong-paediatric-cases-in-sydney-australia

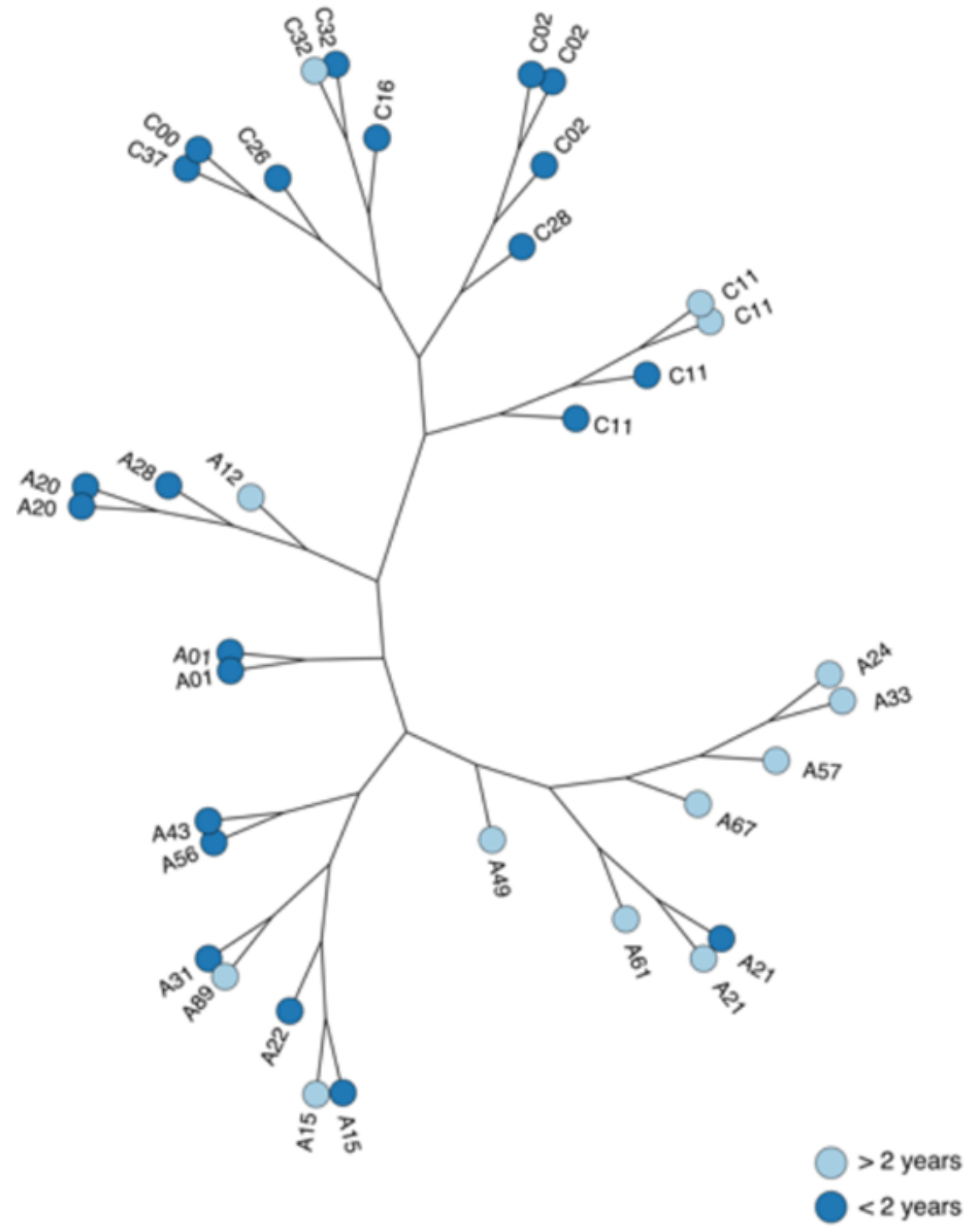

\section{Hosted file}

Table 1.pdf available at https://authorea.com/users/378105/articles/494672-the-molecularepidemiology-and-clinical-phylogenetics-of-rhinoviruses-among-paediatric-cases-insydney-australia

\section{Hosted file}

Table 2.pdf available at https://authorea.com/users/378105/articles/494672-the-molecularepidemiology-and-clinical-phylogenetics-of-rhinoviruses-among-paediatric-cases-insydney-australia

\section{Hosted file}


Table 3.pdf available at https://authorea.com/users/378105/articles/494672-the-molecularepidemiology-and-clinical-phylogenetics-of-rhinoviruses-among-paediatric-cases-insydney-australia

\section{Hosted file}

Table 4.pdf available at https://authorea.com/users/378105/articles/494672-the-molecularepidemiology-and-clinical-phylogenetics-of-rhinoviruses-among-paediatric-cases-insydney-australia 